\title{
"Not in my brain": The use of embolic protection devices to prevent brain embolization during cardiovascular procedures
}

\author{
Juan A. Crestanello, MD
}

\author{
From the Department of Cardiovascular Surgery, Mayo Clinic, Rochester, Minn \\ Disclosures: Author has nothing to disclose with regard to commercial support. \\ Received for publication May 28, 2018; revisions received May 28, 2018; accepted for publication May 30, 2018; \\ available ahead of print July 11, 2018 . \\ Address for reprints: Juan A. Crestanello, MD, Department of Cardiovascular Surgery, Mayo Clinic, 200 First St \\ SW, Rochester, MN 55905 (E-mail: crestanello.juan@mayo.edu). \\ J Thorac Cardiovasc Surg 2018;156:e205-6 \\ $0022-5223 / \$ 36.00$ \\ Copyright (C) 2018 by The American Association for Thoracic Surgery \\ https://doi.org/10.1016/j.jtcvs.2018.05.114
}

In this issue of the Journal, Ranganath and colleagues ${ }^{1}$ creatively used cerebral embolic protection devices (EPDs) routinely used during carotid stenting to prevent embolization to the brain during the removal of an Impella (Abiomed, Danvers, Mass) device that had been used without anticoagulation. The devices captured thromboembolic material, and the patient recovered with no neurologic complications. The medical literature is full of procedures and treatments that have a logical and thoughtful foundation, but their implementation has been associated with increased risk or has been difficult to demonstrate that they achieved their proposed objective. Prophylactic procedures aimed to prevent complications should demonstrate effectiveness, and their implementation should be associated with low risk. There are no more important prophylactic procedures than those aimed to the prevention of clinical or radiologic strokes during cardiovascular procedures.

Clinical strokes after cardiovascular procedures are fortunately rare, but the majority of patients have clinical silent strokes detected on diffusion-weighted magnetic resonance imaging (dw-MRI) of the brain. ${ }^{2} \mathrm{dw}-\mathrm{MRI}$ of the brain typically demonstrates 1 to 5 small $(1-3 \mathrm{~mm})$ bright lesions in $8 \%$ to more than $90 \%$ of patients after cardiovascular procedures (Figure 1). ${ }^{2}$ These lesions represent acute ischemia and may progress to irreversible infarct and tissue loss, although some of them disappear after a few months. ${ }^{2-5}$ Clinical strokes after cardiac surgery, coronary interventions, or transcatheter valve and aortic procedures not only decrease survival but also worsen quality of life. Even patients who experience clinical silent strokes ("bright lesions" on dw-MRI) have poor long-term outcomes with an increased incidence of cognitive dysfunction, dementia, and memory loss. ${ }^{2-5}$

Several attempts have been made to prevent embolic strokes during cardiac surgery and other cardiovascular procedures. In a recent Cardiothoracic Surgical Trials Network-sponsored clinical trial (clinicaltrials.gov

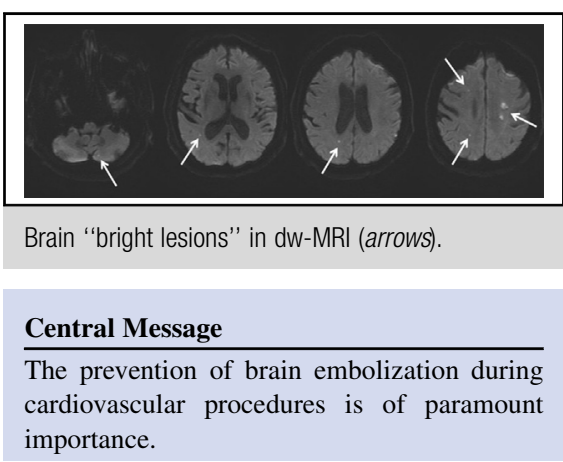

See Article page e203.

Identifier: NCT02389894), the use of cerebral EPD failed to demonstrate a decreased number of clinical or radiologic strokes after isolated surgical aortic valve replacement or combined aortic valve replacement and coronary artery bypass graft surgery. ${ }^{6}$ The study demonstrated that although EDP captured embolic material in $74 \%$ to $99 \%$ of the patients, only $5 \%$ of patients have clinically apparent strokes even with a rigorous stoke adjudication process. Meanwhile, at least $70 \%$ of the patients had new "bright lesions" on dw-MRI, and their incidence was not different between the study and control groups. Similar observations have been made by studies that examined the use of EPD during transcatheter aortic valve replacement: Although EPDs captured embolic material in $99 \%$ of the patients, the rate of clinical and radiologic strokes was similar among the groups. ${ }^{7}$ In some studies, the placement of these devices has been associated with an increased risk of complications because they require manipulation of the inside walls of diseased aortic and carotid vessels. ${ }^{8}$ Likewise, EPDs during carotid stenting are associated with fewer lesions in dwMRI, but the majority of the lesions are not associated with transient ischemic attacks or with minor or major strokes.

Cerebral EPDs have a thoughtful and logical foundation, and their implementation during cardiovascular procedures is associated with low risk, but the effectiveness to reduce clinical or radiologic strokes has not been conclusively demonstrated even when they capture embolic material. Thus, we cannot assume that the presence of thromboembolic material in the EPDs prevented a clinical or radiologic stroke in the current case report. ${ }^{1}$ It is likely that this patient had "bright lesions" on dw-MRI if one had been performed 


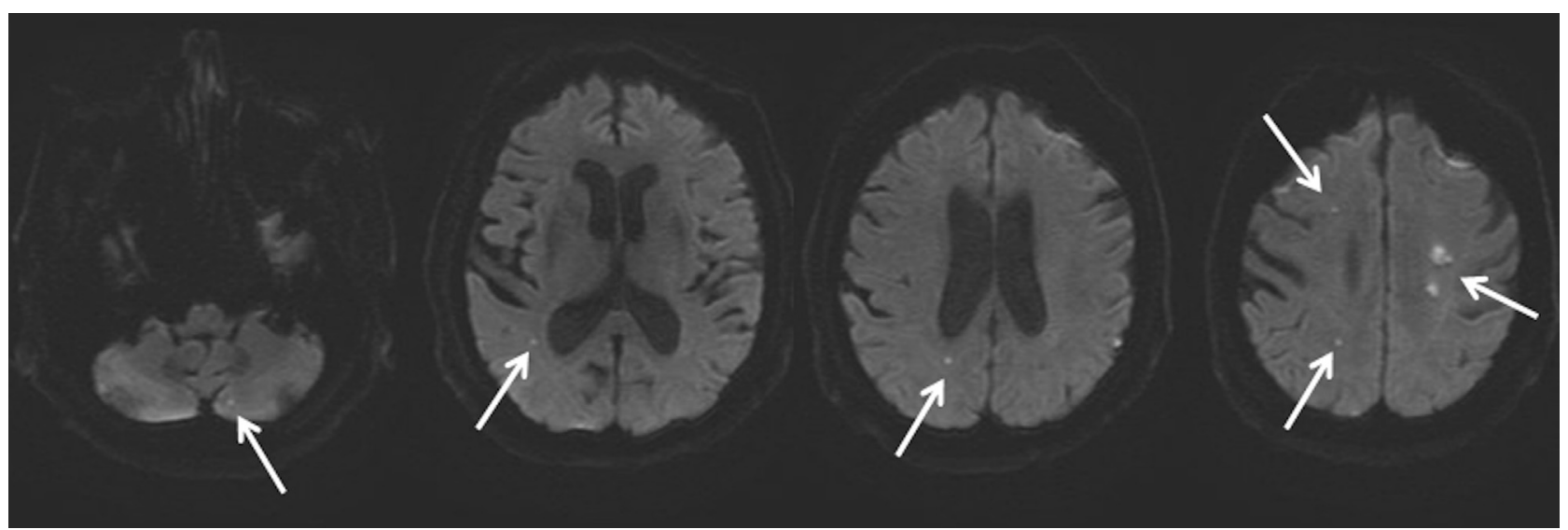

FIGURE 1. Diffusion-weighted magnetic resonance imaging of the brain showing multiple embolic lesions (bright lesions, arrows) after surgical aortic valve replacement.

and may even have had a clinical stroke if a rigorous examination had been performed by a neurologist. Should the EPD have been used? There are no conclusive data to support its use during any cardiovascular procedures and even less during Impella removal. Yet, these "bright lesions" on $\mathrm{dw}-\mathrm{MRI}$ are unlikely to make anybody any brighter because their volume is correlated with worse neuropsychologic and cognitive outcomes. ${ }^{6,7,9}$ Do you want them in your brain? I don't. Cerebral EPDs may not be the solution, but pursuing reduction of brain embolization is of paramount importance because survival is considered an expected outcome, and we and the society focus on quality of life outcomes as the definition of success after cardiovascular procedures.

\section{References}

1. Ranganath NK, Moazami N, Staniloae CS, Hisamoto K. Successful embolic protection during temporary circulatory support device removal in a patient who required holding of anticoagulation for postoperative hemothorax. J Thorac Cardiovasc Surg. 2018;156:e203-4.
2. Gress DR. The problem with asymptomatic cerebral embolic complications in vascular procedures: what if they are not asymptomatic? J Am Coll Cardiol. 2012;60:1614-6.

3. Meller SM, Baumbach A, Brickman AM, Lansky AJ. Clinical implications for diffusion-weighted MRI brain lesions associated with transcatheter aortic valve replacement. Catheter Cardiovasc Interv. 2014;83:502-8.

4. Lansky AJ, Brown D, Pena C, Pietras CG, Parise H, Ng VG, et al. Neurologic complications of unprotected transcatheter aortic valve implantation (from the NeuroTAVI Trial). Am J Cardiol. 2016;118:1519-26.

5. Kobayashi T, Giri J. The role of embolic protection in carotid stenting progress in cardiovascular diseases (PCVD). Prog Cardiovasc Dis. 2017;59:612-8.

6. Mack MJ, Acker MA, Gelijns AC, Overbey JR, Parides MK, Browndyke JN, et al. Cardiothoracic surgical trials network (CTSN). Effect of cerebral embolic protection devices on CNS infarction in surgical aortic valve replacement: a randomized clinical trial. JAMA. 2017;318:536-47.

7. Kapadia SR, Kodali S, Makkar R, Mehran R, Lazar RM, Zivadinov R, et al; SENTINEL Trial Investigators. Protection against cerebral embolism during transcatheter aortic valve replacement. J Am Coll Cardiol. 2017;69:367-77.

8. Awad H, Hackett K, Ramadan ME, Crestanello J. Con: routine use of embolic filters in transcatheter aortic valve replacement is not indicated. J Cardiothorac Vasc Anesth. 2018;32:1056-61.

9. Lazar RM, Pavol MA, Bormann T, Dwyer MG, Kraemer C, White R, et al. Neurocognition and cerebral lesion burden in high-risk patients before undergoing transcatheter aortic valve replacement. J Am Coll Cardiol Intv. 2018;11:384-92. 